\title{
Hamiltonian Analysis of a Hydro-energy Generation System in the transient of sudden load increasing
}

\author{
Huanhuan $\mathrm{Li}^{1}$, Diyi Chen ${ }^{1,2}$, Hao Zhang ${ }^{1}$, Changzhi Wu ${ }^{2}$, Xiangyu Wang ${ }^{2,3}$ \\ ${ }^{1}$ Institute of Water Resources and Hydropower Research, Northwest A\&F University, \\ Shaanxi Yangling 712100, P. R. China \\ ${ }^{2}$ Australasian Joint Research Centre for Building Information Modelling, School of \\ Built Environment, Curtin University, WA, 6102, Australia \\ ${ }^{3}$ Department of Housing and Interior Design, Kyung Hee University, Seoul, Korea
}

Corresponding author: Diyi Chen

Telephones: 086-181-6198-0277

E-mail: diyichen@nwsuaf.edu.cn

Abstract: This paper addresses the Hamiltonian mathematical modeling and dynamic analysis of a hydro-energy generation system in the transient of sudden load increasing. First, six dynamic transfer coefficients of the hydro-turbine for the transient of sudden load increasing are innovatively introduced into the hydro-energy generation system. Considering the elastic water-hammer model of the penstock and third-order model of the generator, we established a dynamic mathematical model of the hydro-energy generation system in the transient of sudden load increasing. Moreover, from the point of view of the transmission and dissipation of energy of the system, we propose the hydro-energy generation system into the theory frame of the generalized Hamiltonian system. A novel Hamiltonian model of the hydro-energy generation system is established utilizing the method of orthogonal decomposition. Finally, based on the data of a real hydropower plant, numerical simulations and 
physical experiment are carried out, and the results indicates that the Hamiltonian system can reflect the essence of the nonlinearity of the hydro-energy generation system in the transient of sudden load increasing. More importantly, these methods and results will supply theoretical basis for designing and running a hydropower plant.

Keywords: hydro-energy generation system; Hamiltonian function; transient of sudden load increasing; dynamic transfer coefficients

\section{Introduction}

The development of economy and technology puts forward higher request to the reliability of electrical power supply [1-5]. The stability of the power system is directly related to the safety, reliability and availability of the power system [2-8]. The hydro-energy generation system (HEGS), as an important part of the power system, affects the power transmission and safe operation of the hydropower plant [9-15]. In the actual operation, due to the flow inertia of the penstock, the disturbance of the stochastic load and the sudden changing of the load, the vibration and the self-excitation of the HEGS will become more prominent [16-27]. Therefore, it is important to study the dynamic characteristics of the HEGS.

The Hamiltonian system, which is an open generalized system, has the energy dissipation and energy exchange with the outside environment. It can better describe the energy dissipation, the energy produced from the interior of the system and the energy supplied from the environment $[10-11,23]$. The HEGS is a typical open system, which can better reflect the transmission and dissipation of energy [10, 28-31]. 
From the point of view of the transmission and dissipation of energy, putting the HEGS into the theory frame of the generalized Hamiltonian system is a new research approach to study the energy characteristics of the HEGS [23-40]. In previous studies, few published papers however focus on the investigation of the Hamiltonian model of the HEGS in large fluctuation processes. Most literatures address the Hamiltonian modeling in small fluctuation processes by utilizing the jump function or Gaussian function to indicate the dynamic characteristics and energy changing of the HEGS. According to Ref. [10-11, 18, 23-25, 29], Tab. 1 is made to indicate the benefits and drawbacks of the existing Hamiltonian models of the HEGS. Apparently, these methods cannot better reflect the essence of the nonlinearity of the HEGS in large fluctuation processes. Therefore, establishing a proper Hamiltonian mathematical model of the HEGS and investigating the corresponding dynamic characteristics are of great significance for theory and industry practice.

Tab. 1. Assessment of the existing Hamiltonian models of the HEGS

\begin{tabular}{|c|c|}
\hline \multicolumn{2}{|c|}{ Existing Hamiltonian Models of the HEGS } \\
\hline Benefits & Drawbacks \\
\hline $\begin{array}{l}\text { The model can better reflect the } \\
\text { characteristics of the Hamiltonian system } \\
\text { in the small fluctuation process. }\end{array}$ & $\begin{array}{l}\text { The Hamiltonian model cannot describe } \\
\text { the characteristics of large fluctuation } \\
\text { processes well. }\end{array}$ \\
\hline $\begin{array}{l}\text { Some typical nonlinear elements } \\
\text { including stochastic electrical load, } \\
\text { hydraulic exciting force, etc., are } \\
\text { considered. }\end{array}$ & $\begin{array}{l}\text { The more complex } \\
\text { electromechanical relation cannot be } \\
\text { contained. }\end{array}$ \\
\hline $\begin{array}{l}\text { The dynamic behaviors of the } \\
\text { Hamiltonian system are researched by }\end{array}$ & $\begin{array}{l}\text { The introduced random function cannot } \\
\text { truly describe the dynamic change of the } \\
\text { hydropower system with time. }\end{array}$ \\
\hline
\end{tabular}

Motivated by the above discussions, we have three advantages which make our approach attractive, comparing with the prior work. First, we creatively introduce six 
dynamic transfer coefficients of the hydro-turbine into the HEGS and consider the essence of the nonlinearity of the system, the dynamic mathematical model of the HEGS in the transient of sudden load increasing is established. Second, the mathematical model of the HEGS is converted to a novel Hamiltonian system by putting the HEGS to the theory frame of the generalized Hamiltonian system and using the method of orthogonal decomposition. Finally, we carry out numerical simulations and physical experiment based on the data of an existent hydropower plant. The detailed information of energy changing and the dynamic characteristics of the HEGS for the transient of sudden load increasing are exhaustedly investigated.

The rest of the paper is organized as follows. In Section 2, a novel Hamiltonian mathematical model of the HEGS for the transient of sudden load increasing is established. The established Hamiltonian system is detailed discussed in Section 3. A comparison between the numerical and experimental simulations has been made to prove the validity of the proposed model of the HEGS in Section 4. Section 5 gives some useful conclusions. Discussion in Section 6 closes the paper. 


\begin{tabular}{|c|c|c|c|}
\hline \multicolumn{4}{|c|}{ Nomenclature } \\
\hline$M_{t}$ & $\begin{array}{l}\text { the mechanical torque of } \\
\text { the hydro-turbine, N.m }\end{array}$ & $\begin{array}{l}h_{w} \\
T_{a b}\end{array}$ & $\begin{array}{l}\text { the characteristic coefficient of the pipeline } \\
\text { the mechanical starting time, } \mathrm{s}\end{array}$ \\
\hline$Q$ & $\begin{array}{l}\text { the hydro-turbine flow, } \\
\mathrm{m}^{3} / \mathrm{s}\end{array}$ & $P_{m}$ & $\begin{array}{l}\text { the relative value of the output power of the } \\
\text { hydro-turbine }\end{array}$ \\
\hline $\begin{array}{l}H \\
n\end{array}$ & $\begin{array}{l}\text { the hydro-turbine head, m } \\
\text { the hydro-turbine speed, }\end{array}$ & $P_{m c}$ & $\begin{array}{l}\text { the relative value of the measured output } \\
\text { power of the hydro-turbine }\end{array}$ \\
\hline$a$ & $\begin{array}{l}\mathrm{rad} / \mathrm{s} \\
\text { the guide vane opening, } \\
\mathrm{rad}\end{array}$ & $\begin{array}{l}e_{m x}, \mathrm{e}_{m \mathrm{y}} \\
e_{m \mathrm{~h}}\end{array}$ & $\begin{array}{l}\text { the relative values of the hydro-turbine } \\
\text { torque as regards the hydro-turbine speed, } \\
\text { the hydro-turbine guide vane and the }\end{array}$ \\
\hline$m_{t}$ & $\begin{array}{l}\text { the relative value of the } \\
\text { mechanical torque, p.u }\end{array}$ & $e_{q x}, e_{q y}$ & $\begin{array}{l}\text { hydro-turbine head, p.u. } \\
\text { the relative values of the flc }\end{array}$ \\
\hline$h$ & $\begin{array}{l}\text { the relative value of the } \\
\text { hydro-turbine head, p.u }\end{array}$ & $e_{q h}$ & $\begin{array}{l}\text { bine speed, the hydro-turbine } \\
\text { the hydro-turbine head, p.u. }\end{array}$ \\
\hline$x$ & $\begin{array}{l}\text { the relative value of the } \\
\text { hydro-turbine speed, p.u }\end{array}$ & $\begin{array}{l}k_{p} \\
k_{i}\end{array}$ & $\begin{array}{l}\text { ustment coefficient } \\
\text { ent coefficient }\end{array}$ \\
\hline$q$ & $\begin{array}{l}\text { the relative value of the } \\
\text { hydro-turbine flow, p.u }\end{array}$ & $\begin{array}{l}k_{d} \\
u\end{array}$ & t coefficient \\
\hline$q_{c}$ & $\begin{array}{l}\text { the relative value of the } \\
\text { measured hydro-turbine } \\
\text { flow }\end{array}$ & $\begin{array}{l}m_{e} \\
P_{e} \\
E_{q}^{\prime}\end{array}$ & $\begin{array}{l}\text { the electromagnetic torque of the generator } \\
\text { the electromagnetic power of the generator } \\
\text { the transient internal voltage of armature }\end{array}$ \\
\hline$y$ & the relative value of the & $V_{s}$ & \\
\hline & guide vane opening, p.u. & $x_{d}$ & is transient reactance \\
\hline$x_{1}, x_{2}$ & intermediate variables & $x_{q}$ & d axis reactanc \\
\hline$x_{3}$ & & $E_{f}$ & itation controller, p.u. \\
\hline$\omega$ & $\begin{array}{l}\text { the relative value of the } \\
\text { generator rotor speed, p.u. }\end{array}$ & $H_{1}$ & $\begin{array}{l}\text { the Hamitonian function for the } \\
\text { hydro-turbine }\end{array}$ \\
\hline$\delta$ & $\begin{array}{l}\text { the relative value of the } \\
\text { rotor angle, rad }\end{array}$ & $\begin{array}{l}\mathrm{H}_{2} \\
\mathrm{H}\end{array}$ & $\begin{array}{l}\text { the Hamitonian function for the generator } \\
\text { the Hamitonian function for the HEGS }\end{array}$ \\
\hline$T_{y}$ & $\begin{array}{l}\text { the engager relay time } \\
\text { constant, } \mathrm{s}\end{array}$ & $\begin{array}{l}J(x) \\
P(x)\end{array}$ & $\begin{array}{l}\text { the anti-symmetric matrix } \\
\text { the symmetric matrix }\end{array}$ \\
\hline$T_{r}$ & the elastic water hammer & $X_{f}$ & the exciting winding reactance \\
\hline$D$ & $\begin{array}{l}\text { time constant, s } \\
\text { the damping coefficient }\end{array}$ & $X_{a d}$ & the $d$ axis armature reaction reactance \\
\hline
\end{tabular}

\section{The Hamiltonian model of the HEGS in the transient of sudden}

\section{load increasing}

The HEGS composed of a control system and a controlled system as shown in 
Fig. $1[15,23]$, contains the synchronous generator, the hydro-turbine, the governor and the penstock.

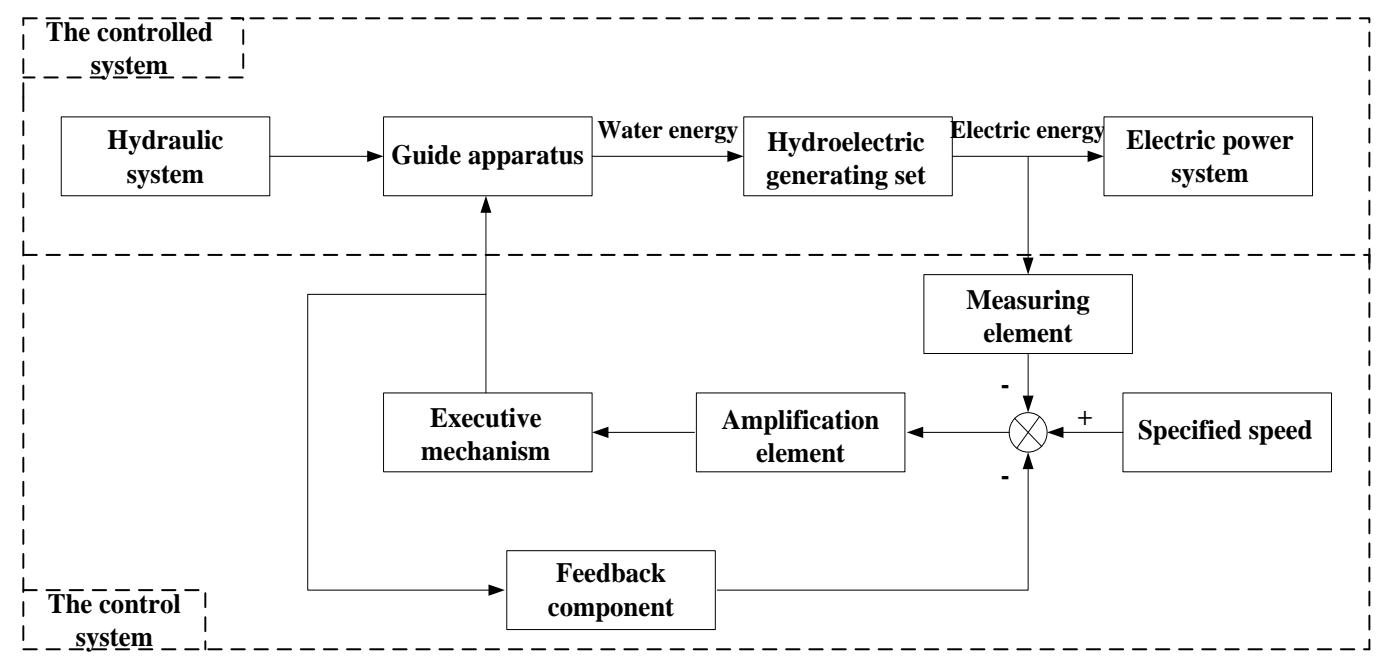

Fig. 1. The structure diagram of the HEGS.

\subsection{The joint model of the hydro-turbine and the hydraulic speed regulation}

\section{system}

\subsubsection{Dynamic transfer coefficients of the hydro-turbine}

Generally, we obtain the mathematical model of the hydro-turbine utilizing the internal characteristics method, external characteristics method or simple analytical method. Here, the internal characteristics method is used due to its high accuracy [6, 18-19, 29].

The mathematical model of the HEGS including the transfer coefficients of the hydro-turbine is shown in Fig. 2 [15]. 


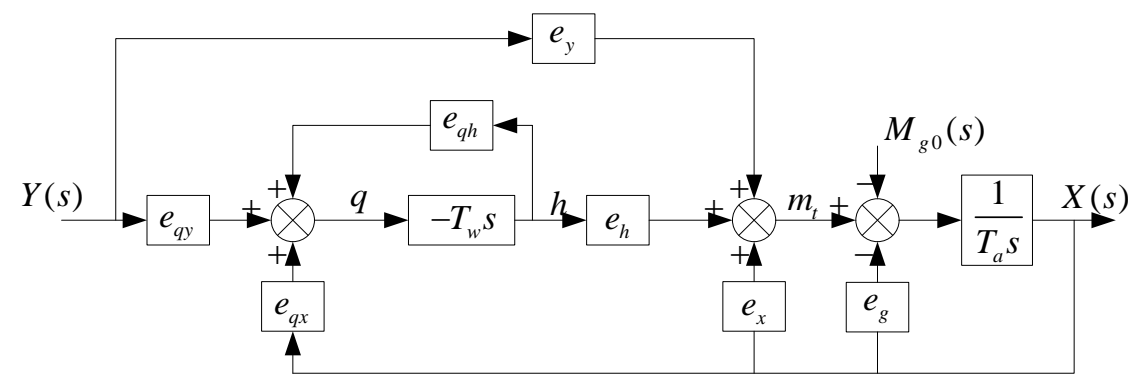

Fig. 2. The structure diagram of the HEGS including the transfer coefficients of the hydro-turbine.

Using the internal characteristics method, the dynamic characteristics of a Francis hydro-turbine [18] can be described as

$$
\left\{\begin{array}{l}
M_{t}=M_{t}(H, n, a) \\
Q=Q(H, n, a)
\end{array},\right.
$$

where $M_{t}, Q, H, n$ and $a$ denote the mechanical torque of the hydro-turbine, the hydro-turbine flow, the hydro-turbine head, the hydro-turbine speed and the guide vane opening, respectively.

Using the Taylor series expansion, Eq. (1) can be rewritten as

$$
\left\{\begin{array}{l}
\frac{M_{t}-M_{t 0}}{M_{t R}}=\frac{\partial \frac{M_{t}}{M_{t R}}}{\partial \frac{n}{n_{R}}} \frac{n-n_{0}}{n_{R}}+\frac{\partial \frac{M_{t}}{M_{t R}}}{\partial \frac{a}{a_{\max }}} \frac{a-a_{0}}{a_{\max }}+\frac{\partial \frac{M_{t}}{M_{t R}}}{\partial \frac{H}{H_{R}}} \frac{H-H_{0}}{H_{R}} \\
\frac{Q-Q_{0}}{Q_{R}}=\frac{\partial \frac{Q}{Q_{R}}}{\partial \frac{n}{n_{R}}} \frac{a-a_{0}}{n_{R}}+\frac{\partial \frac{Q}{Q_{R}}}{\partial \frac{a}{a_{\max }}} \frac{a-a_{0}}{a_{\max }}+\frac{\partial \frac{Q}{Q_{R}}}{\partial \frac{H}{H_{R}}} \frac{a-a_{0}}{H_{R}}
\end{array},\right.
$$

where subscripts $R$ and $O$ denote the actual value of rated condition and the actual value of steady condition, respectively. $\frac{\partial \frac{M_{t}}{M_{t R}}}{\partial \frac{n}{n_{\max }}}=\frac{\partial m_{t}}{\partial x}, \frac{\partial \frac{M_{t}}{M_{t R}}}{\partial \frac{a}{a_{\max }}}=\frac{\partial m_{t}}{\partial y}, \frac{\partial \frac{M_{t}}{M_{t R}}}{\partial \frac{H}{H_{\max }}}=\frac{\partial m_{t}}{\partial h}$ 


$$
\begin{gathered}
\frac{\partial \frac{Q}{Q_{R}}}{\partial \frac{n}{n_{\max }}}=\frac{\partial q}{\partial x}, \frac{\partial \frac{Q}{Q_{R}}}{\partial \frac{a}{a_{\max }}}=\frac{\partial q}{\partial y} \text { and } \frac{\partial \frac{Q}{Q_{R}}}{\partial \frac{H}{H_{\max }}}=\frac{\partial q}{\partial h} \text {. Thus, Eq. (2) can be expressed as } \\
\left\{\begin{array}{l}
\frac{\Delta M_{t}}{M_{t R}}=\frac{\partial m_{t}}{\partial x} \frac{n-n_{0}}{n_{R}}+\frac{\partial m_{t}}{\partial y} \frac{a-a_{0}}{a_{\max }}+\frac{\partial m_{t}}{\partial h} \frac{H-H_{0}}{H_{R}} \\
\frac{\Delta Q}{Q_{R}}=\frac{\partial q}{\partial x} \frac{a-a_{0}}{n_{R}}+\frac{\partial q}{\partial y} \frac{a-a_{0}}{a_{\max }}+\frac{\partial q}{\partial h} \frac{a-a_{0}}{H_{R}}
\end{array}\right.
\end{gathered}
$$

Suppose that the guide vane opening $a$ is equal to the main servomotor stroke $Y$ in Eq. (3). The transfer coefficients of the hydro-turbine can be rewritten as

$$
\left\{\begin{array}{c}
m_{t}=e_{m w} x+e_{m y} y+e_{m h} h \\
q=e_{q w} x+e_{q y} y+e_{q h} h
\end{array}\right.
$$

where $m_{t}, q, h, x$ and $y$ represent the corresponding relative values of the hydro-turbine torque, the hydro-turbine flow, the hydro-turbine head, the hydro-turbine speed and the hydro-turbine guide vane opening, respectively. $e_{m w}$, $e_{m y}$ and $e_{m h}$ respectively denote the relative values of the hydro-turbine torque as regards the hydro-turbine speed, the hydro-turbine guide vane and the hydro-turbine head. $e_{q w}, e_{q y}$ and $e_{q h}$ are the relative values of the flow with respect to the hydro-turbine speed, the hydro-turbine guide vane and the hydro-turbine head, respectively.

According to Eq. (4), the dynamic transfer coefficients of the hydro-turbine with time $t$ for the transient of sudden load increasing are introduced, which are expressed 


$$
\left\{\begin{array}{l}
e_{m y}=\frac{1}{5} \cos 4 \pi t+2 e^{-t}+\frac{8}{5} \\
e_{m w}=\frac{1}{10} \cos 4 \pi t+\frac{9}{10} e^{-t}-\frac{7}{10} \\
e_{m h}=\frac{4}{25} \cos 4 \pi t-\frac{19}{10} e^{-t}+\frac{17}{10} \\
e_{q y}=\frac{2}{25} \sin 4 \pi t+\frac{4}{5} e^{-t}+\frac{7}{5} \\
e_{q w}=\frac{1}{50} \sin 4 \pi t+\frac{21}{100} e^{-t}-\frac{3}{20} \\
e_{q h}=\frac{1}{25} \sin 4 \pi t-\frac{13}{30} e^{-t}+\frac{3}{5}
\end{array} .\right.
$$

\subsubsection{Dynamic equation of the hydro-turbine output torque}

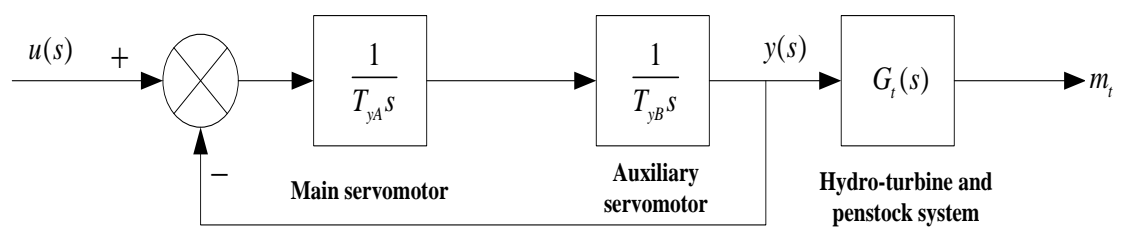

Fig. 3. The mechanism of the hydro-turbine and the penstock system.

As demonstrated in Fig. 3 [15], considering the elastic water-hammer impact of the penstock, the transfer function between the hydro-turbine guide vane and the hydro-turbine output torque [29] is written as

$$
G_{t}(s)=-\frac{e_{m y}}{e_{q h}} \cdot \frac{e s^{3}-\frac{3}{h_{w} T_{r}} s^{2}+\frac{24 e}{T_{r}^{2}} s-\frac{24}{h_{w} T_{r}^{3}}}{s^{3}+\frac{3}{e_{q h} h_{w} T_{r}} s^{2}+\frac{24}{T_{r}^{2}} s+\frac{24}{e_{q h} h_{w} T_{r}^{3}}},
$$

where $e$ is an intermediate variable, $e=\frac{e_{q y} e_{m h}}{e_{m y}}-e_{q h} . h_{w}$ and $T_{r}$ are the characteristic coefficient pipeline and the elastic water hammer time constant, respectively.

The state-space equations of Eq. (6) are shown as 


$$
\left\{\begin{array}{l}
\dot{x}_{1}=x_{2} \\
\dot{x}_{2}=x_{3} \\
\dot{x}_{3}=-a_{0} x_{1}-a_{1} x_{2}-a_{2} x_{3}+y
\end{array} .\right.
$$

The dynamic equation of the hydro-turbine output torque is described as

$$
m_{t}=b_{3} y+\left(b_{0}-a_{0} b_{3}\right) x_{1}+\left(b_{1}-a_{1} b_{3}\right) x_{2}+\left(b_{2}-a_{2} b_{3}\right) x_{3},
$$

and its power is

$$
P_{m}=\omega m_{t}
$$

where $\quad a_{0}=\frac{24}{e_{q h} h_{w} T_{r}^{3}}, \quad a_{1}=\frac{24}{T_{r}^{2}}, \quad a_{2}=\frac{3}{e_{q h} h_{w} T_{r}}, \quad b_{0}=\frac{24 e_{m y}}{e_{q h} h_{w} T_{r}^{3}}, \quad b_{1}=\frac{24 e e_{m y}}{e_{q h} T_{r}^{2}} ，$ $b_{2}=\frac{3 e_{m y}}{e_{q h} h_{w} T_{r}}$ and $b_{3}=-\frac{e e_{m y}}{e_{q h}} . x_{1}, x_{2}$ and $x_{3}$ represent the intermediate variables.

\subsubsection{The mathematical model of the hydraulic speed regulation system}

From Refs. [15, 18-19], the dynamic characteristics of the hydraulic speed regulation system can be expressed as

$$
T_{y} \frac{d y}{d t}+y=u
$$

where $T_{y}$ and $u$ respectively denote the engager relay time constant and the output of the regulator.

Here, a universal parallel PID governor [6, 25-27] is considered. Subsequently, the dynamic characteristics of the hydraulic speed regulation system can be shown as

$$
\frac{d y}{d t}=\frac{1}{T_{y}}\left(-k_{p} \omega-\frac{k_{i}}{\omega_{0}} \delta-k_{d} \dot{\omega}-y\right) \text {. }
$$

\subsubsection{The Hamiltonian model of the hydro-turbine and the hydraulic speed regulation} system 
From the above discussions, the joint model of the hydro-turbine and the hydraulic speed regulation system for the transient of sudden load increasing is

$$
\begin{aligned}
\dot{x}_{1}= & x_{2} \\
\dot{x}_{2}= & x_{3} \\
\dot{x}_{3}= & -\frac{24}{\left(\frac{1}{25} \sin 4 \pi t-\frac{13}{30} e^{-t}+\frac{3}{5}\right) h_{w} T_{r}^{3}} x_{1}-\frac{24}{T_{r}^{2}} x_{2}-\frac{3}{\left(\frac{1}{25} \sin 4 \pi t-\frac{13}{30} e^{-t}+\frac{3}{5}\right) h_{w} T_{r}} x_{3}+y \\
\dot{q}= & \left(\frac{1}{50} \sin 4 \pi t+\frac{21}{100} e^{-t}-\frac{3}{20}\right) \frac{\dot{\omega}}{2 \pi}+\left(\frac{2}{25} \sin 4 \pi t+\frac{4}{5} e^{-t}+\frac{7}{5}\right) \dot{y}+\left(\frac{1}{25} \sin 4 \pi t-\frac{13}{30} e^{-t}+\frac{3}{5}\right) \dot{h} \\
& +\left((2 \pi \cos (4 \pi t)) / 25-21 /\left(100 e^{t}\right)\right) \frac{\omega}{2 \pi}+\left((8 \pi \cos (4 \pi t)) / 25-4 /\left(5 e^{-t}\right)\right) y \\
& +\left(13 /\left(30 e^{t}\right)+(4 \pi \cos (4 \pi t)) / 25\right) h \\
\dot{h}= & \left(\left(\dot{m}_{t}+\left(9 /\left(10 e^{-t}\right)-(2 \pi \sin (4 \pi t)) / 5\right) \frac{\omega}{2 \pi}-\left(\frac{1}{10} \cos 4 \pi t+\frac{9}{10} e^{-t}-\frac{7}{10}\right) \frac{\dot{\omega}}{2 \pi}\right.\right. \\
& \left.+\left(2 / e^{-t}-(4 \pi \sin (4 \pi t)) / 5\right) y-\left(\frac{1}{5} \cos 4 \pi t+2 e^{-t}+\frac{8}{5}\right) \dot{y}\right)\left(\frac{4}{25} \cos 4 \pi t-\frac{19}{10} e^{-t}+\frac{17}{10}\right) \\
& -\left(19 /\left(10 e^{-t}\right)-(16 \pi \sin (4 \pi t)) / 25\right)\left(m_{t}-\left(\frac{1}{10} \cos 4 \pi t+\frac{9}{10} e^{-t}-\frac{7}{10}\right) \frac{\omega}{2 \pi}\right. \\
& \left.\left.-\left(\frac{1}{5} \cos 4 \pi t+2 e^{-t}+\frac{8}{5}\right) y\right)\right) /\left(\frac{4}{25} \cos 4 \pi t-\frac{19}{10} e^{-t}+\frac{17}{10}\right)^{2} \\
\dot{y}= & \frac{1}{T_{y}}(u-y)
\end{aligned}
$$

Subsequently, Eq. (12) is converted to an affine nonlinear function, which is

$$
\dot{X}=f(x)+g(x) u
$$

where $\dot{X}=\left[\dot{x}_{1}, \dot{x}_{2}, \dot{x}_{3}, \dot{q}, \dot{h}, \dot{y}\right]^{T}, \quad g(x)=\left[0,0,0,0,0, \frac{1}{T_{y}}\right]^{T}$,

and 


$$
f(x)=\left[\begin{array}{l}
x_{2} \\
x_{3} \\
-\frac{24}{\left(\frac{1}{25} \sin 4 \pi t-\frac{13}{30} e^{-t}+\frac{3}{5}\right) h_{w} T_{r}^{3}} x_{1}-\frac{24}{T_{r}^{2}} x_{2}-\frac{3}{\left(\frac{1}{25} \sin 4 \pi t-\frac{13}{30} e^{-t}+\frac{3}{5}\right) h_{w} T_{r}} x_{3}+y \\
\left(\frac{1}{50} \sin 4 \pi t+\frac{21}{100} e^{-t}-\frac{3}{20}\right) \frac{\dot{\omega}}{2 \pi}+\left(\frac{2}{25} \sin 4 \pi t+\frac{4}{5} e^{-t}+\frac{7}{5}\right) \dot{y}+\left(\frac{1}{25} \sin 4 \pi t-\frac{13}{30} e^{-t}+\frac{3}{5}\right) \dot{h} \\
\quad+\left((2 \pi \cos (4 \pi t)) / 25-21 /\left(100 e^{t}\right)\right) \frac{\omega}{2 \pi}+\left((8 \pi \cos (4 \pi t)) / 25-4 /\left(5 e^{-t}\right)\right) y \\
\quad+\left(13 /\left(30 e^{t}\right)+(4 \pi \cos (4 \pi t)) / 25\right) h \\
\left(\dot{m}_{t}+\left(9 /\left(10 e^{-t}\right)-(2 \pi \sin (4 \pi t)) / 5\right) \frac{\omega}{2 \pi}-\left(\frac{1}{10} \cos 4 \pi t+\frac{9}{10} e^{-t}-\frac{7}{10}\right) \frac{\dot{\omega}}{2 \pi}\right. \\
\left.\quad+\left(2 / e^{-t}-(4 \pi \sin (4 \pi t)) / 5\right) y-\left(\frac{1}{5} \cos 4 \pi t+2 e^{-t}+\frac{8}{5}\right) \dot{y}\right)\left(\frac{4}{25} \cos 4 \pi t-\frac{19}{10} e^{-t}+\frac{17}{10}\right) \\
\quad-\left(19 /\left(10 e^{-t}\right)-(16 \pi \sin (4 \pi t)) / 25\right)\left(m_{t}-\left(\frac{1}{10} \cos 4 \pi t+\frac{9}{10} e^{-t}-\frac{7}{10}\right) \frac{\omega}{2 \pi}\right. \\
\left.\left.\quad-\left(\frac{1}{5} \cos 4 \pi t+2 e^{-t}+\frac{8}{5}\right) y\right)\right) /\left(\frac{4}{25} \cos 4 \pi t-\frac{19}{10} e^{-t}+\frac{17}{10}\right)^{2} \\
-y \frac{1}{T_{y}}
\end{array}\right]
$$

Utilizing the formula $g(x)^{T} \frac{\partial H_{1}}{\partial X}=-P_{m}$, the Hamiltonian function of the hydro-turbine is obtained as

$$
H_{1}=\left(T_{y} y\left(2 b_{0} x_{1}+2 b_{1} x_{2}+2 b_{2} x_{3}+b_{3} y-2 a_{0} b_{3} x_{1}-2 a_{1} b_{3} x_{2}-2 a_{2} b_{3} x_{3}\right)\right) / 2 .
$$

From Ref. [23], Eq. (13) is transformed into the Hamiltonian mathematical model, which is

$$
\dot{X}=[J(x)+P(x)] \frac{\partial H_{1}}{\partial x}+g(x) u
$$

where $J(x)$ is the anti-symmetric matrix,

$$
J(x)=\left[\begin{array}{cccccc}
0 & j_{12} & j_{13} & j_{14} & j_{15} & j_{16} \\
-j_{12} & 0 & j_{23} & j_{24} & j_{25} & j_{26} \\
-j_{13} & -j_{23} & 0 & j_{34} & j_{35} & j_{36} \\
-j_{14} & -j_{24} & -j_{34} & 0 & j_{45} & j_{46} \\
-j_{15} & -j_{25} & -j_{35} & -j_{45} & 0 & j_{56} \\
-j_{16} & -j_{26} & -j_{36} & -j_{46} & -j_{56} & 0
\end{array}\right] ; \quad P(x) \text { is the symmetric matrix, }
$$


$P(x)=\left[\begin{array}{cccccc}p & 0 & 0 & 0 & 0 & 0 \\ 0 & p & 0 & 0 & 0 & 0 \\ 0 & 0 & p & 0 & 0 & 0 \\ 0 & 0 & 0 & p & 0 & 0 \\ 0 & 0 & 0 & 0 & p & 0 \\ 0 & 0 & 0 & 0 & 0 & p\end{array}\right]$. The detailed computational method for $J(x)$ and $P(x)$ can be obtained in Refs. [10-11, 23].

The symmetric matrix $P(x)$ is further decomposed into the following form [11]

$$
P(x)=\frac{1}{\left\|\nabla H_{1}(x)\right\|^{2}}\left\langle f(x), \nabla H_{1}\right\rangle=S(x)-R(x),
$$

where

$$
S(x)=\left[\begin{array}{cccccc}
s(x) & 0 & 0 & 0 & 0 & 0 \\
0 & s(x) & 0 & 0 & 0 & 0 \\
0 & 0 & s(x) & 0 & 0 & 0 \\
0 & 0 & 0 & s(x) & 0 & 0 \\
0 & 0 & 0 & 0 & s(x) & 0 \\
0 & 0 & 0 & 0 & 0 & s(x)
\end{array}\right]
$$

and

$$
R(x)=\left[\begin{array}{cccccc}
r(x) & 0 & 0 & 0 & 0 & 0 \\
0 & r(x) & 0 & 0 & 0 & 0 \\
0 & 0 & r(x) & 0 & 0 & 0 \\
0 & 0 & 0 & r(x) & 0 & 0 \\
0 & 0 & 0 & 0 & r(x) & 0 \\
0 & 0 & 0 & 0 & 0 & r(x)
\end{array}\right] \text {. Therefore, the Hamiltonian }
$$

mathematical model of the hydro-turbine is rewritten as

$$
\dot{X}_{1}=[J(x)+S(x)-R(x)] \frac{\partial H_{1}}{\partial x}+g(x) u .
$$

\subsection{The Hamiltonian mathematical model of the generator}

In this paper, we consider a third-order mathematical model of the generator $[18-19,29]$, which is shown as 


$$
\left\{\begin{array}{l}
\dot{\delta}=\omega_{0}(\omega-1) \\
\dot{\omega}=\frac{1}{T_{a b}}\left(m_{t}-P_{e}-D(\omega-1)\right) \\
\dot{E}_{q}^{\prime}=-\frac{\omega_{0}}{T_{d}} \frac{x_{d \Sigma}}{x_{d \Sigma}^{\prime}} E_{q}^{\prime}+\frac{\omega_{0}}{T_{d}} \frac{x_{d \Sigma}-x_{d \Sigma}^{\prime}}{x_{d \Sigma}^{\prime}} V_{s} \cos \delta+\frac{\omega_{0}}{T_{d}} E_{f}
\end{array},\right.
$$

where $\delta, \omega, D, T_{a b}, E_{q}^{\prime}, V_{s}, T_{d}, E_{f}, x_{d}^{\prime}$ and $x_{q}$ denote the rotor angle, the deviation of the generator rotor speed, the damping coefficient, the mechanical starting time, the transient internal voltage of armature, the voltage of infinite bus, the transient time constant of axis $d$, the output of excitation controller, the direct axis transient reactance and the quartered axis reactance, respectively.

Here, the electromagnetic power of the generator $P_{e}$ is expressed as

$$
P_{e}=\frac{E_{q}^{\prime} V_{s}}{x_{d \Sigma}^{\prime}} \sin \delta+\frac{V_{s}^{2}}{2} \frac{x_{d \Sigma}^{\prime}-x_{q \Sigma}}{x_{d \Sigma}^{\prime} x_{q \Sigma}} \sin 2 \delta .
$$

$x_{d \Sigma}^{\prime}$ and $x_{q \Sigma}$ are calculated with the following formulas

$$
\left\{\begin{array}{l}
x_{d \Sigma}^{\prime}=\dot{x}_{d}+x_{T}+\frac{1}{2} x_{L} \\
x_{q \Sigma}=x_{q}+x_{T}+\frac{1}{2} x_{L}
\end{array}\right.
$$

where $x_{T}$ and $x_{L}$ represent the short-circuit reactance of transformer and the transmission line reactance, respectively.

From Ref. [10], the Hamiltonian mathematical model of the third-order generator is

$$
\left[\begin{array}{c}
\dot{\delta} \\
\dot{\omega} \\
\dot{E}_{q}^{\prime}
\end{array}\right]=\left[\begin{array}{ccc}
0 & C_{1} & 0 \\
-C_{1} & -C_{D} & 0 \\
0 & 0 & -C_{G}
\end{array}\right]\left[\begin{array}{c}
\frac{\partial H_{2}}{\partial \delta} \\
\frac{\partial H_{2}}{\partial \omega} \\
\frac{\partial H_{2}}{\partial E_{q}^{\prime}}
\end{array}\right]+\left[\begin{array}{cc}
A & 0 \\
0 & \frac{\omega_{0}}{T_{d}}
\end{array}{ }_{E_{f}}^{m_{t}}\right] .
$$


The Hamiltonian function of the generator is expressed as

$$
H_{2}=\frac{T_{a b}}{2} \omega^{2}+\frac{V_{s}^{2}}{2} \frac{x_{q \Sigma}-x_{d \Sigma}}{x_{q \Sigma} x_{d \Sigma}} \cos ^{2} \delta+\frac{V_{s}^{2}}{2 x_{q \Sigma}}+\frac{1}{2 x_{d \Sigma}^{\prime} x_{d \Sigma} X_{f}}\left(X_{a d} V_{s} \cos \delta-x_{d \Sigma} \frac{X_{f}}{X_{a d}} E_{q}^{\prime}\right)^{2},
$$

where $X_{f}$ and $X_{a d}$ denote the exciting winding reactance and the $d$ axis armature reaction reactance, respectively.

\subsection{The Hamiltonian mathematical model of the HEGS}

From the above analyses and discussions, we combine the different components into a single system. Thus, the mathematical model of the HEGS in the transient of sudden load increasing is obtained as

$$
\begin{aligned}
\dot{x}_{1}= & x_{2} \\
\dot{x}_{2}= & x_{3} \\
\dot{x}_{3}= & -\frac{24}{\left(\frac{1}{25} \sin 4 \pi t-\frac{13}{30} e^{-t}+\frac{3}{5}\right) h_{w} T_{r}^{3}} x_{1}-\frac{24}{T_{r}^{2}} x_{2}-\frac{3}{\left(\frac{1}{25} \sin 4 \pi t-\frac{13}{30} e^{-t}+\frac{3}{5}\right) h_{w} T_{r}} x_{3}+y \\
\dot{q}= & \left(\frac{1}{50} \sin 4 \pi t+\frac{21}{100} e^{-t}-\frac{3}{20}\right) \frac{\dot{\omega}}{2 \pi}+\left(\frac{2}{25} \sin 4 \pi t+\frac{4}{5} e^{-t}+\frac{7}{5}\right) \dot{y}+\left(\frac{1}{25} \sin 4 \pi t-\frac{13}{30} e^{-t}+\frac{3}{5}\right) \dot{h} \\
& +\left((2 \pi \cos (4 \pi t)) / 25-21 /\left(100 e^{t}\right)\right) \frac{\omega}{2 \pi}+\left((8 \pi \cos (4 \pi t)) / 25-4 /\left(5 e^{-t}\right)\right) y \\
& +\left(13 /\left(30 e^{t}\right)+(4 \pi \cos (4 \pi t)) / 25\right) h \\
\dot{h}= & \left(\left(\dot{m}_{t}+\left(9 /\left(10 e^{-t}\right)-(2 \pi \sin (4 \pi t)) / 5\right) \frac{\omega}{2 \pi}-\left(\frac{1}{10} \cos 4 \pi t+\frac{9}{10} e^{-t}-\frac{7}{10}\right) \frac{\dot{\omega}}{2 \pi}\right.\right. \\
& \left.+\left(2 / e^{-t}-(4 \pi \sin (4 \pi t)) / 5\right) y-\left(\frac{1}{5} \cos 4 \pi t+2 e^{-t}+\frac{8}{5}\right) \dot{y}\right)\left(\frac{4}{25} \cos 4 \pi t-\frac{19}{10} e^{-t}+\frac{17}{10}\right) \\
& -\left(19 /\left(10 e^{-t}\right)-(16 \pi \sin (4 \pi t)) / 25\right)\left(m_{t}-\left(\frac{1}{10} \cos 4 \pi t+\frac{9}{10} e^{-t}-\frac{7}{10}\right) \frac{\omega}{2 \pi}\right. \\
& \left.\left.-\left(\frac{1}{5} \cos 4 \pi t+2 e^{-t}+\frac{8}{5}\right) y\right)\right) /\left(\frac{4}{25} \cos 4 \pi t-\frac{19}{10} e^{-t}+\frac{17}{10}\right)^{2} \\
\dot{y}= & \frac{1}{T_{y}}(u-y) \\
\dot{\delta}= & \omega_{0}(\omega-1) \\
\dot{\omega}= & \frac{1}{T_{a b}}\left(m_{t}-P_{e}-D(\omega-1)\right) \\
\dot{E}_{q}^{\prime}= & -\frac{\omega_{0}}{T_{d}} \frac{x_{d \Sigma}}{x_{d \Sigma}^{\prime}} E_{q}^{\prime}+\frac{\omega_{0}}{T_{d}} \frac{x_{d \Sigma}-x_{d \Sigma}^{\prime}}{x_{d \Sigma}^{\prime}} V_{s} \cos \delta+\frac{\omega_{0}}{T_{d}} E_{f}
\end{aligned}
$$

The Hamiltonian mathematical model of the HEGS in the transient of sudden load 
increasing is

$$
\dot{X}=[J(x)+S(x)-R(x)] \frac{\partial H}{\partial x}+g(x) u,
$$

where $\dot{X}=\left[\dot{x}_{1}, \dot{x}_{2}, \dot{x}_{3}, \dot{q}, \dot{h}, \dot{y}, \dot{\delta}, \dot{\omega}, \dot{E}_{q}^{\prime}\right] . H$ is the Hamiltonian function of the HEGS,

$$
\begin{aligned}
H= & H_{1}+H_{2} \\
= & \left(T_{y} y\left(2 b_{0} x_{1}+2 b_{1} x_{2}+2 b_{2} x_{3}+b_{3} y-2 a_{0} b_{3} x_{1}-2 a_{1} b_{3} x_{2}-2 a_{2} b_{3} x_{3}\right)\right) / 2+\frac{T_{a b}}{2} \omega^{2} . \\
& +\frac{V_{s}^{2}}{2} \frac{x_{q \Sigma}-x_{d \Sigma}}{x_{q \Sigma} x_{d \Sigma}} \cos ^{2} \delta+\frac{V_{s}^{2}}{2 x_{q \Sigma}}+\frac{1}{2 x_{d \Sigma}^{\prime} x_{d \Sigma} X_{f}}\left(X_{a d} V_{s} \cos \delta-x_{d \Sigma} \frac{X_{f}}{X_{a d}} E_{q}^{\prime}\right)^{2}
\end{aligned}
$$

\section{Numerical experiments}

\subsection{Experiment parameters of the HEGS}

In this paper, we use the data of a real hydropower plant in China to investigate the dynamic characteristics and the detailed information of energy changing of the HEGS. Moreover, the PID parameters are $k_{p}=5, k_{i}=2.5$ and $k_{d}=1.5$, and the basic parameters of the HEGS are shown in Tab. 2 [10-11, 23-24].

Tab. 2. Basic parameters of the HEGS

\begin{tabular}{ccccccccccccc}
\hline Basic & $x_{d \Sigma}^{\prime}$ & $x_{q \Sigma}$ & $T_{d}$ & $T_{y}$ & $V_{s}$ & $X_{a d}$ & $X_{f}$ & $T_{a b}$ & $D$ & $T_{r}$ & $h_{w}$ \\
parameters & & & & & & & & & & & \\
\hline Values & 0.6775 & 0.9975 & 5.4 & 0.5 & 1 & 0.97 & 1.29 & 8.999 & 5 & 0.8 & 2 \\
\hline
\end{tabular}

\subsection{Numerical experiments and dynamic analyzing of the Hamiltonian system}

In this section, the numerical experiments of the established Hamiltonian system for the transient of sudden load increasing are carried out, and the corresponding numerical results are shown in Figure. 4 and Figure 5. 


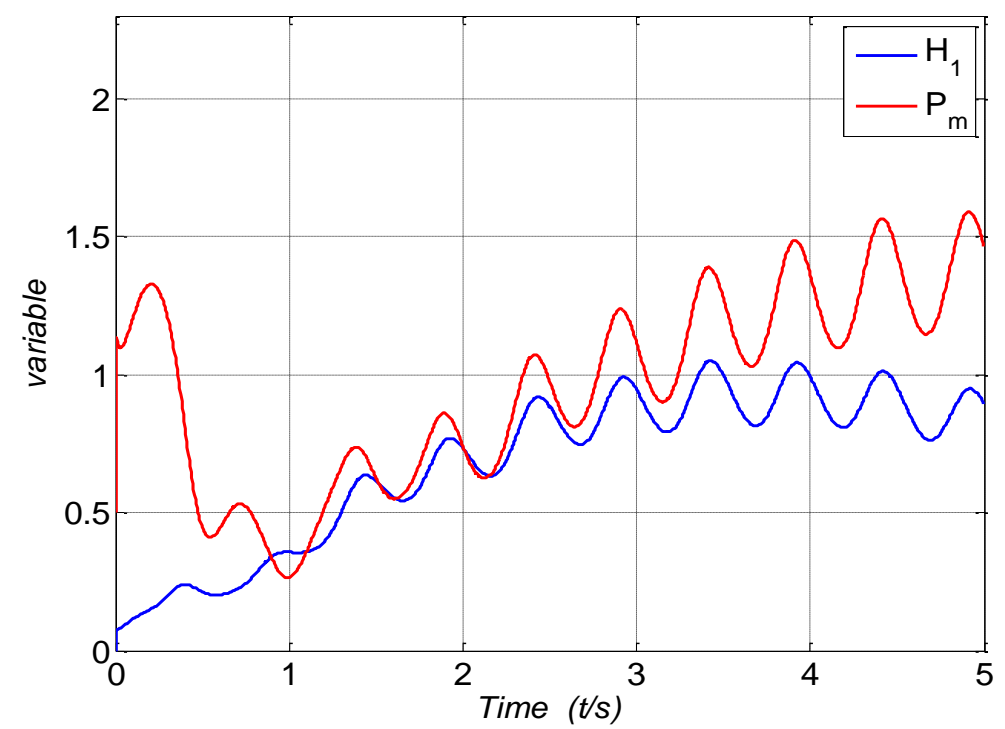

(a) Responses of the Hamiltonian function $\left(H_{1}\right)$ and the output power $\left(P_{m}\right)$ for the

hydro-turbine.

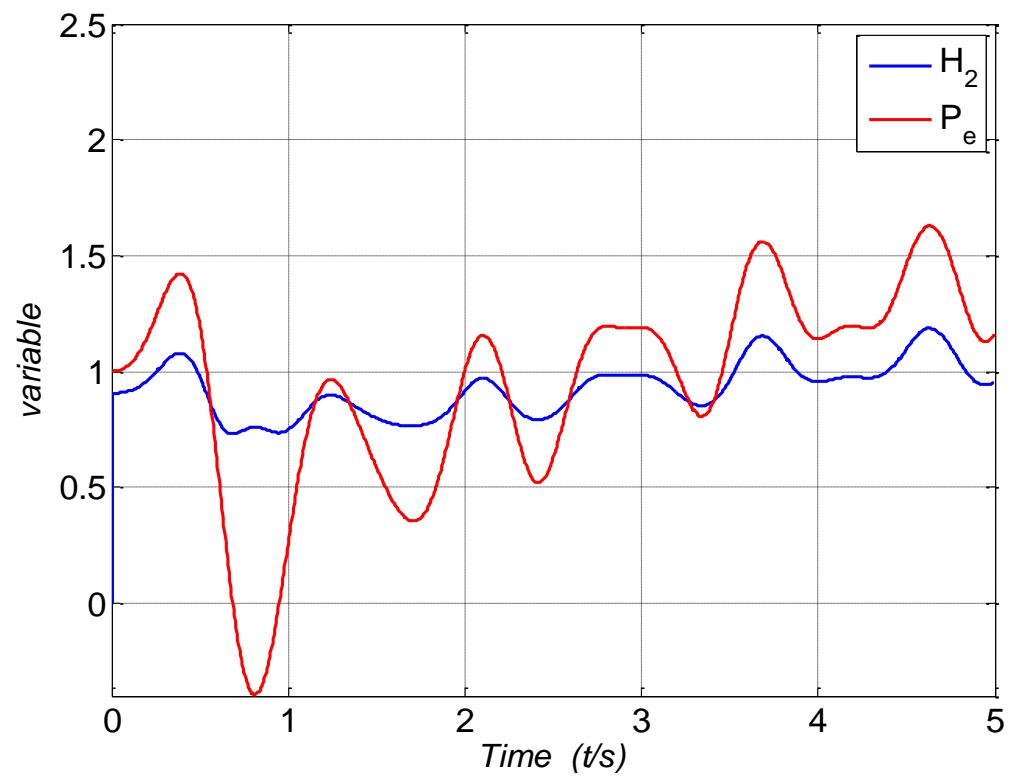

(b) Responses of the Hamiltonian function $\left(H_{2}\right)$ and the electromagnetic power $\left(P_{e}\right)$ for the generator. 


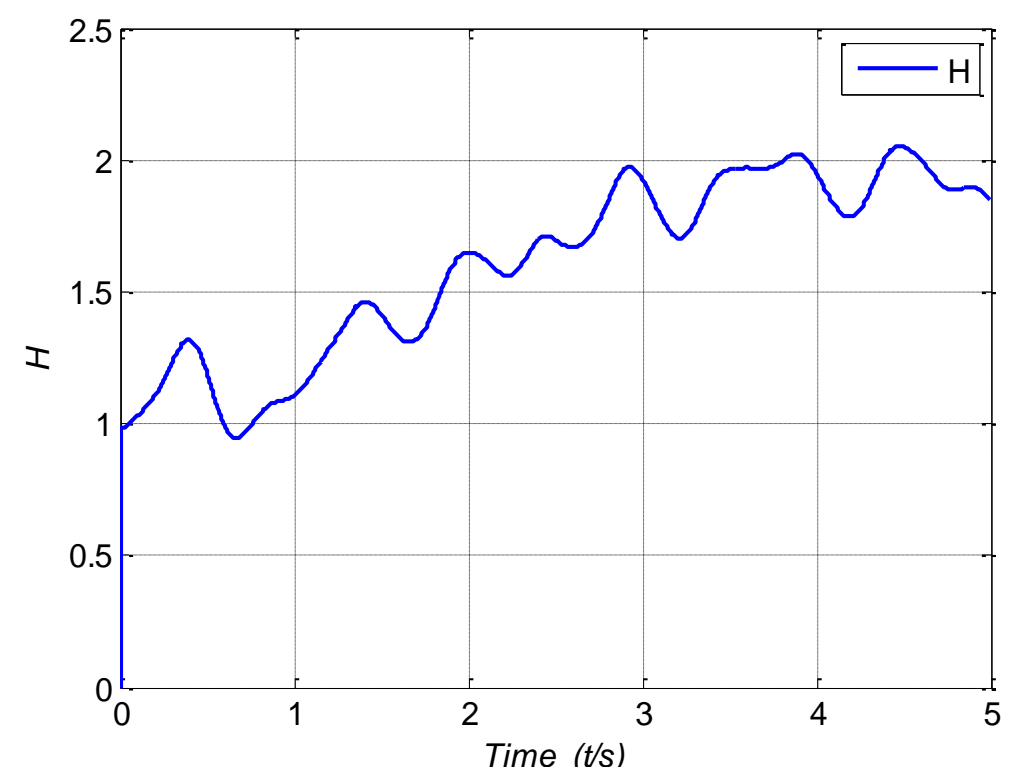

(c) Response of the Hamiltonian function $(H)$ for the HEGS.

Fig. 4. Responds of the dynamic variables of the Hamiltonian system in the transient of sudden load increasing. (a) Responses of the Hamiltonian function $\left(H_{1}\right)$ and the output power $\left(P_{m}\right)$ for the hydro-turbine; $(b)$ Responses of the Hamiltonian function $\left(H_{2}\right)$ and the electromagnetic power $\left(P_{e}\right)$ for the generator; $(c)$ Response of the Hamiltonian function $(H)$ for the HEGS.

Fig. 4 shows the corresponding responses of the dynamic variables for the hydro-turbine, the generator and the HEGS in the transient of sudden load increasing, respectively. From Fig. 4(a), for the hydro-turbine, the general trend of the Hamiltonian function $\left(H_{1}\right)$ and output power $\left(P_{m}\right)$ is increasing. Moreover, note that the apparent fluctuation of the output power $\left(P_{m}\right)$ appears due to the selection of the dynamic transfer coefficients of the hydro-turbine. Fig. 4(b) shows, for the generator, its Hamiltonian function $\left(\mathrm{H}_{2}\right)$ and electromagnetic power $\left(P_{e}\right)$ are in the same tendency, which both fluctuate in the whole transient of sudden load increasing. As shown in Fig. 4(c), the Hamiltonian function $(H)$ of the HEGS increases gradually with time $t$ in the transient of sudden load increasing, which is caused by the increase 
of the output power of the generation system. All of the above phenomena mean that the Hamiltonian function of the established system can describe the main information of dynamic behaviors of the HEGS in the transient of sudden load increasing.

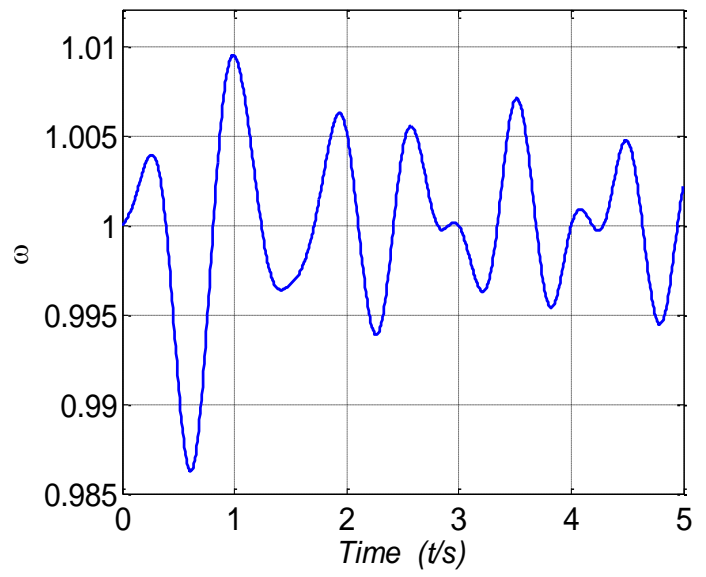

(a) $\omega-t$

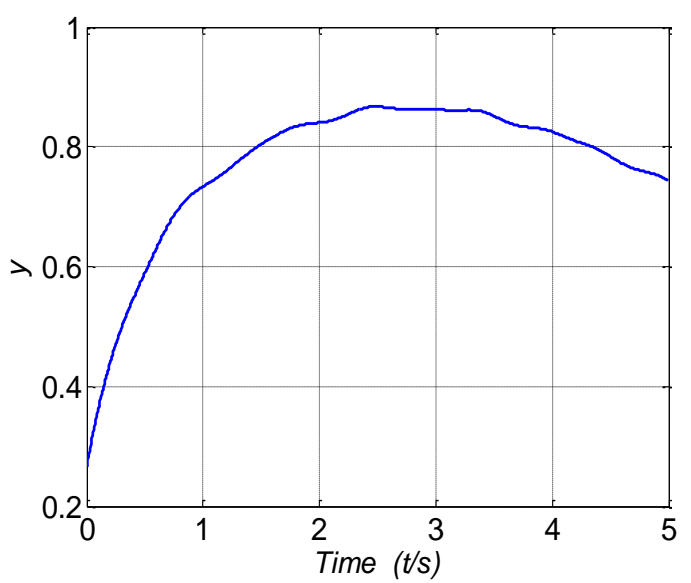

(c) $y-t$

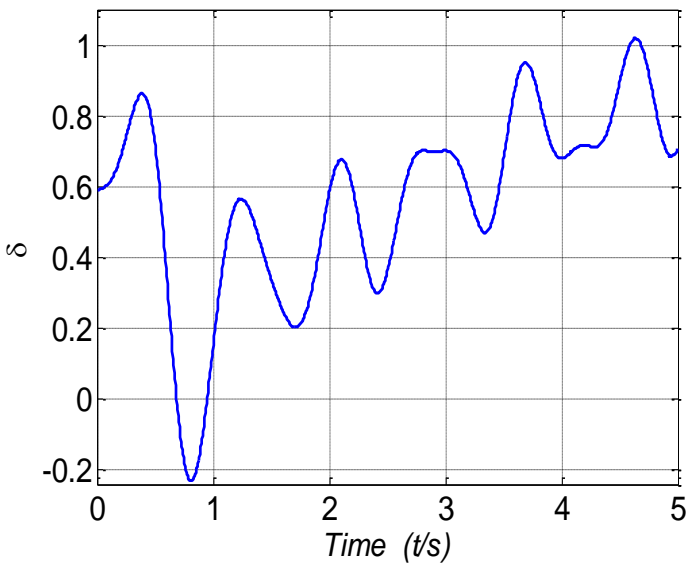

(b) $\delta-t$

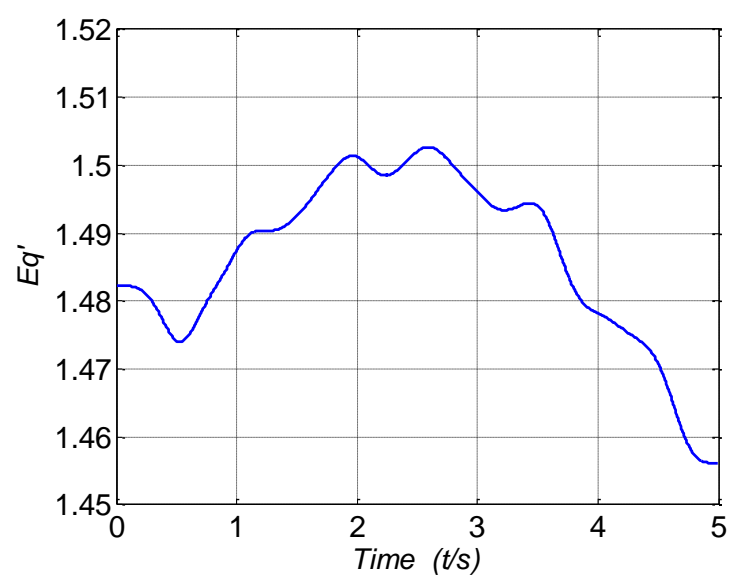

(d) $E_{q}^{\prime}-t$

Fig. 5. Change laws of dynamic parameters of the established Hamiltonian system in the transient of sudden load increasing. (a) $\omega-t ;(e) \delta-t ;(c) \quad y-t ;(d) \quad E_{q}^{\prime}-t$.

To deeply reveal the dynamic characteristics of the HEGS in the transient of sudden load increasing, the change laws of dynamic parameters of the established Hamiltonian system are shown in Fig. 5. It is clearly observed that, in the transient of sudden load increasing, due to the sudden changing of the load, the guide vane 
opening increases gradually with time $t$. Subsequently, the hydro-turbine flow and the mechanical torque of the hydro-turbine both increase. It leads to the decreases of the pressure of the penstock and the internal transient voltage. Note that the reciprocating oscillation of the hydro-turbine rotor speed and the power-angle of the generator both appear and the hydro-turbine rotor speed fluctuates slightly. The reason is that the HEGS connects with the power system in the whole transient of sudden load increasing. All of the above phenomena are identical with the corresponding theories and engineering practices, which means that the established Hamiltonian system can better reflect the essence of the nonlinearity of the HEGS in the transient of sudden load increasing.

\section{Model validation}

In this section, a comparison between the numerical and experimental simulations has been made to prove the validity of the proposed model of the HEGS.

First, the basic system information of the real hydropower plant in China is shown in Tab. 3 [41].

Tab. 3. Basic system information of the real hydropower plant

\begin{tabular}{|c|c|c|c|}
\hline $\begin{array}{c}\text { The installed capacity } \\
\text { of the hydro-turbine }\end{array}$ & $150 \mathrm{MW}$ & $\begin{array}{c}\text { The nominal output } \\
\text { power }\end{array}$ & $153 \mathrm{MW}$ \\
\hline The hydro-turbine type & HL99.5-LJ-344.2 & The nominal flow & $53.5 \mathrm{~m}^{3} / \mathrm{s}$ \\
\hline The nominal speed & $333.3 \mathrm{rpm}$ & $\begin{array}{c}\text { The weighted average } \\
\text { efficiency under design } \\
\text { head }\end{array}$ & $93.77 \%$ \\
\hline The nominal head & $312 \mathrm{~m}$ & & \\
\hline
\end{tabular}

Second, in order to obtain the experimental data, an experimental platform of the HEGS in the transient of sudden load increasing is built, as shown in Fig. 6. 


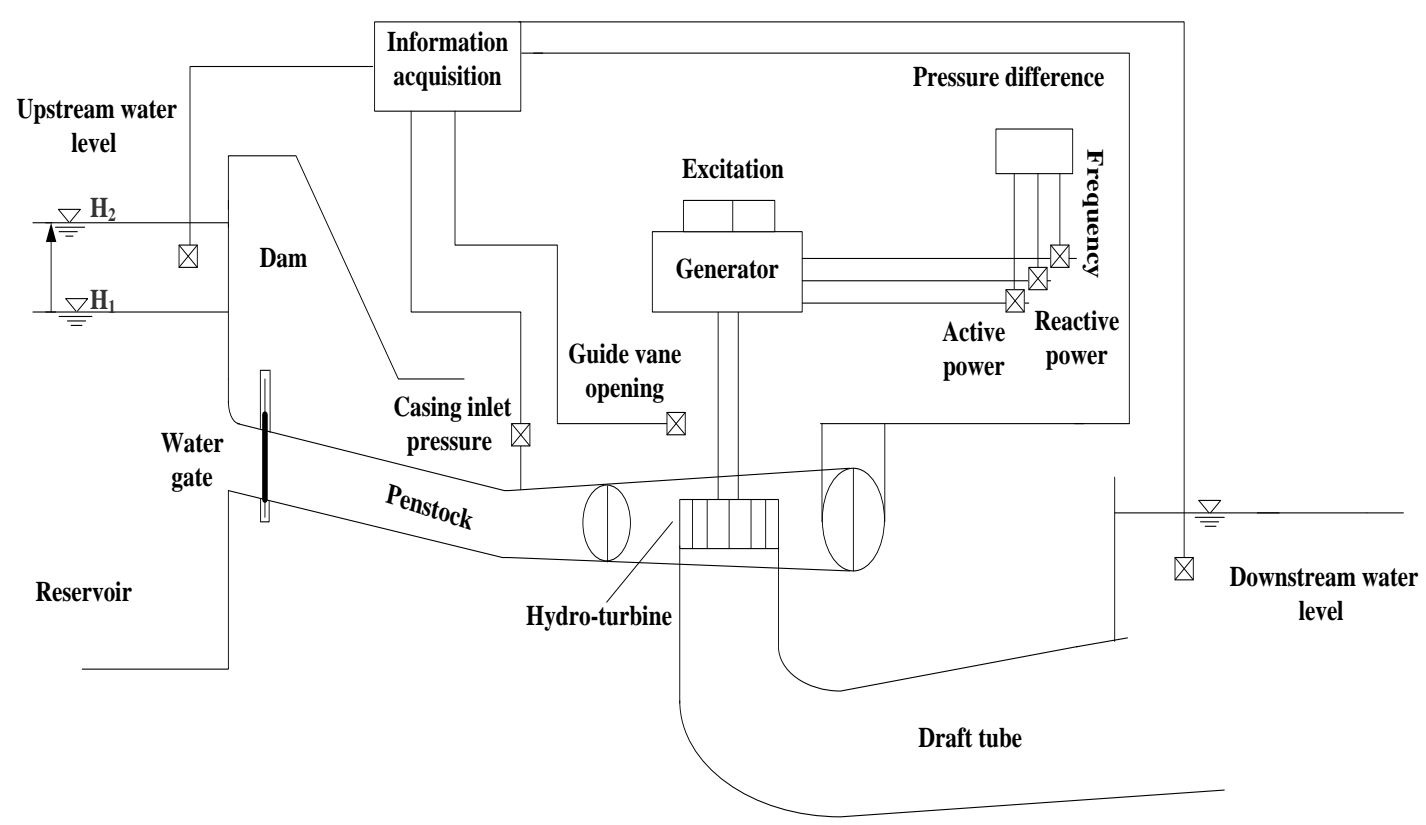

Fig. 6. The experimental platform of the HEGS.

As demonstrated in Fig. 6, when the reservoirs water level raises from $H_{1}$ to $H_{2}$, the hydro-turbine flow and the guide vane opening increase, and the system runs with the increasing load $[15,18]$. In this case, through collecting the information of measuring points, the experimental data are obtained. Here, we change the experimental data from the absolute value to the relative value, as shown in Tab. 4 .

Tab. 4. Experimental data of the HEGS

\begin{tabular}{|c|c|c|c|c|c|c|c|c|}
\hline $\begin{array}{c}\text { Time } \\
(\mathrm{s})\end{array}$ & 0 & 0.71 & 1.43 & 2.14 & 2.86 & 3.57 & 4.29 & 5 \\
\hline$P_{m c}$ & 0.4486 & 0.5624 & 0.6864 & 0.7976 & 0.9229 & 0.9305 & 1.0402 & 1.2 \\
\hline$q_{c}$ & 0.4398 & 0.5327 & 0.6368 & 0.7303 & 0.8376 & 0.848 & 0.9361 & 1.1 \\
\hline
\end{tabular}

$* P_{m c}$ denotes the relative value of the measured output power; $q_{c}$ is the relative value of the measured hydro-turbine flow

Finally, the fitting curve of output power $P_{m c}$ is acquired from the experimental data of $P_{m c}$. Based on the above work, we make a comparison between the numerical 
output power $P_{m}$ and experimental output power $P_{m c}$ in the transient of sudden load increasing, as shown in Fig. 7.

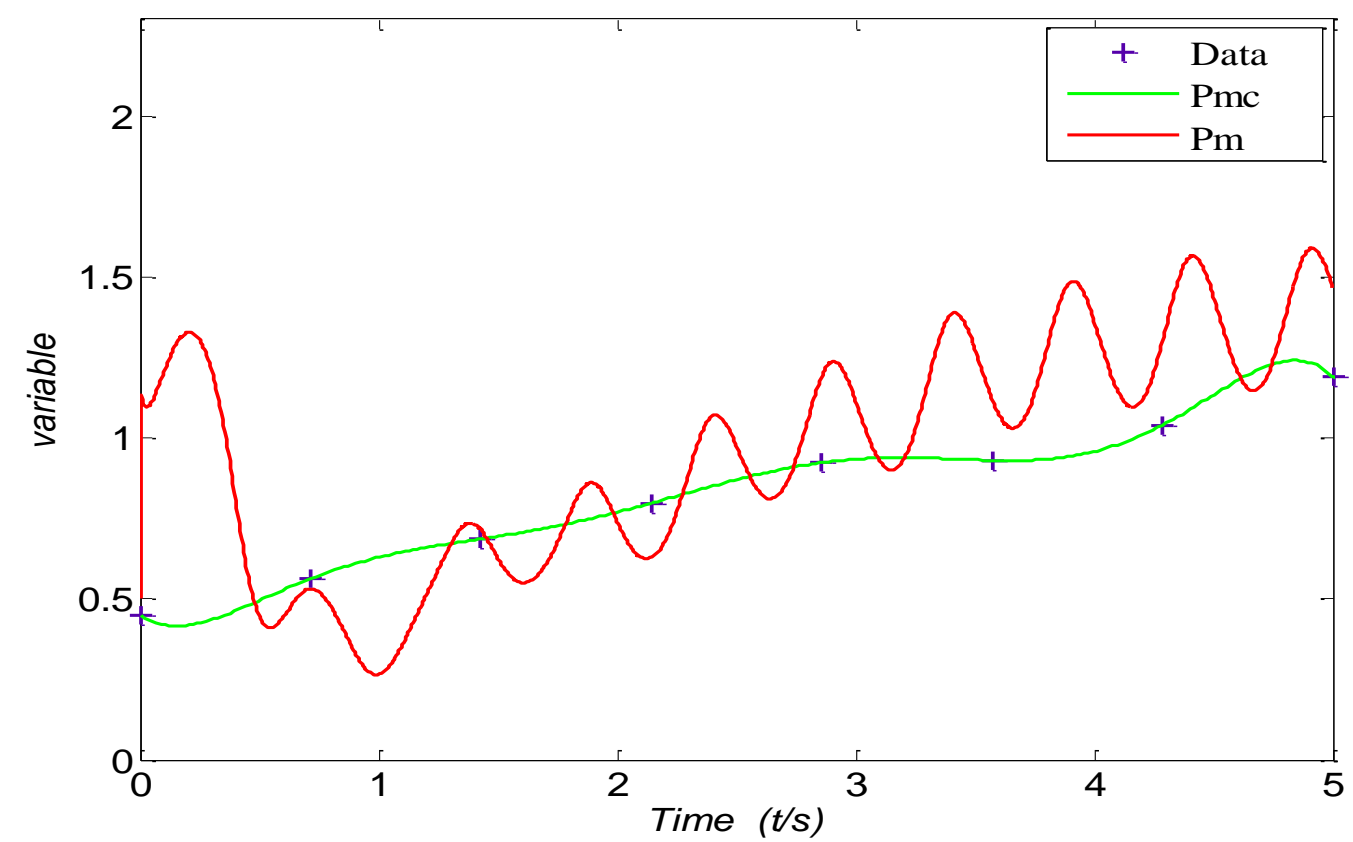

Fig. 7. A comparison between the numerical output power $P_{m}$ and experimental output power $P_{m c}$ in the transient of sudden load increasing.

From Fig. 7, the general changing trend of numerical output power $P_{m}$ is consistent with that for experimental output power $P_{m c}$, and they both increase in the transient of sudden load increasing. Note that the numerical output power $P_{m}$ and experimental output power $P_{m c}$ have some deviations for $0<t<0.47$. There are two fundamental factors could contribute to this phenomenon. The first is that the nonlinear system has higher sensitivity to initial conditions. The second is that the selection of transfer coefficients of the hydro-turbine has subtle error at $0<t<0.47$. However, it's worth mentioning that the details of the change for fitting curve of output power $P_{m c}$ cannot be better shown because of the finite number of experimental data points. It means that the fitting curve of output power $P_{m c}$ cannot 
reflect the fluctuation of output power $P_{m c}$, while it can indicates the trend of output power $P_{m c}$. Therefore, we can draw a conclusion that the proposed function is valid.

\section{Remark 1:}

It is well known that, for the previous studies, the step disturbance is often introduced into the Hamiltonian system to reveal the transient dynamic characteristics of the system. To prove the superiority of the established Hamiltonian system for the transient of sudden load increasing, we have made a comparison between a previous model [23] with the step disturbance and the novel Hamiltonian mathematical model of the HEGS.

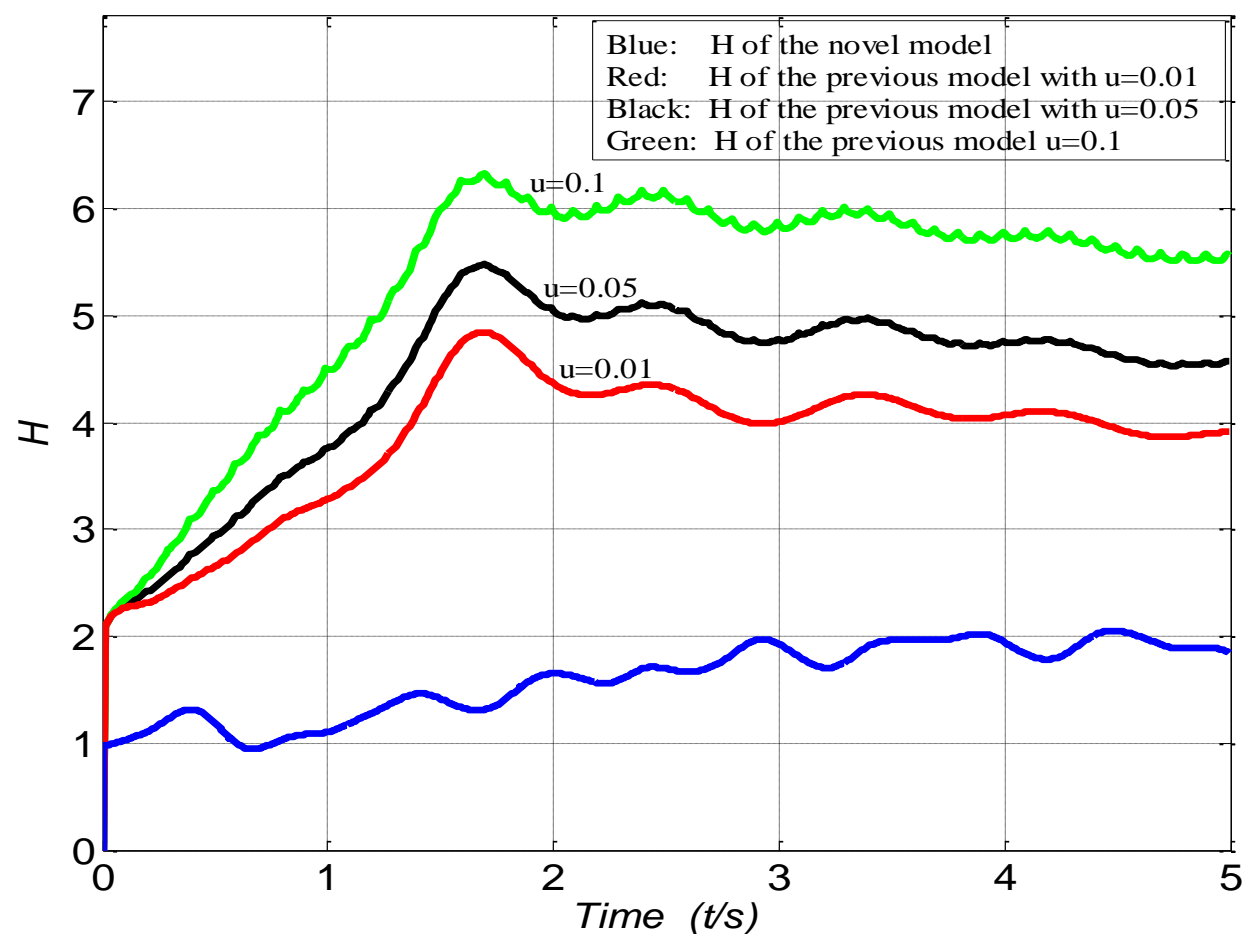

Fig. 8. The comparison between the novel and the previous Hamiltonian system with different step disturbances $(u=0.01, u=0.05, u=0.1)$ in the transient of sudden load increasing.

From Fig. 8, for the novel Hamiltonian model, when $0 \leq t \leq 5$, the Hamiltonian function of the HEGS increases with time $t$. It is noteworthy that, for $0 \leq t \leq 3.5$, the 
fluctuation of the Hamiltonian function of the HEGS is greater than that at the range of $3.5<t \leq 5$. For the previous Hamiltonian system, the waveform of the Hamiltonian function of the HEGS fluctuates markedly with the increase of different step disturbances. The phenomenon indicates that the dynamic characteristics of the HEGS for the previous Hamiltonian system depend on the variation of the step disturbance. Moreover, for different step disturbances, the Hamiltonian functions of the HEGS all increase rapidly in a short time, and then they decrease gradually until $t=5$. In the actual operation of the hydropower station, the Hamiltonian function of the HEGS however increases continuously with the output power of the HEGS increases in the whole transient of sudden load increasing. At the final stage of the transient of sudden load increasing, the Hamiltonian function of the HEGS changes slightly. Therefore, the established Hamiltonian function has significant advantages to reflect the dynamic characteristics of the HEGS in the transient of sudden load increasing. That is to say, the established Hamiltonian system for the transient of sudden load increasing is reasonable.

\section{Conclusions}

In this paper, we have introduced six dynamic transfer coefficients of the hydro-turbine into the HEGS. From the point of view of the transmission and dissipation of energy of the system, we put the HEGS to the theory frame of the generalized Hamiltonian system. Considering the elastic water-hammer impact of the penstock and the nonlinearity of the generator, a novel Hamiltonian mathematical model of the HEGS for the transient of sudden load increasing has been established 
using the method of orthogonal decomposition. Moreover, the numerical and experimental simulations of the established Hamiltonian system have been carried out based on the information of a real hydropower plant.

From the simulation results, we draw the following conclusions. First, the established Hamiltonian function of the HEGS contains detailed information of energy changing of the generation system in the transient of sudden load increasing, which is appropriate. Second, based on the novel Hamiltonian system, the dynamic characteristics of the system for the transient of sudden load increasing are better described. The responses of the dynamic parameters of the system are in good agreement with the corresponding theories and engineering practices. Thus, the established Hamiltonian system is reliable. Finally, we find that the novel Hamiltonian system can be better applied to the large fluctuation process from the comparison between the novel and the previous Hamiltonian system in the transient of sudden load increasing. These methods and results will provide new ideas to the research of the stability of the hydropower station.

\section{Discussion}

The Hamiltonian system which is usually used to carry on the theory research, provides the theoretical guidance for actual operation of the HEGS. Specifically, the theoretical guidance of the Hamiltonian system can be described as follows. Firstly, the Hamiltonian system reflects the energy dissipation and energy exchange with the outside environment, and it can be utilized to analyze the energy flow of the HEGS. Secondly, the Hamiltonian function which is treated as the Lyapunov candidate 
function under some conditions, is used to research the stability of the generation system. Finally, based on the Hamiltonian system, the Hamiltonian controller of the HEGS can be designed to improve the operational stability of the hydropower station.

In our future work, we will attempt to transform the proposed generalized Hamiltonian system to the traditional Hamiltonian system. Meanwhile, we will in-depth investigate the energy characteristics and the dynamic behaviors of the Hamiltonian system in the start-up, shut-down and load rejection transient. Moreover, the different forms of the Hamiltonian function for different transition processes will be discussed.

\section{Acknowledgements}

This work was supported by the scientific research foundation of National Natural Science Foundation--Outstanding Youth Foundation (51622906), National

Science Foundation (51479173), Fundamental Research Funds for the Central Universities (201304030577), Scientific research funds of Northwest A\&F University (2013BSJJ095), the scientific research foundation on water engineering of Shaanxi Province (2013slkj-12), the Science Fund for Excellent Young Scholars from Northwest A\&F University and Shaanxi Nova program (2016KJXX-55).

\section{References}

[1] Kishor N, Saini RP, Singh SP. A review on hydropower plant models and control. Renew. Sust. Energ. Rev. 2007; 11: 776-796. 
[2] Ren JZ, Gao SZ, Tan SY, Dong LC, Scipioni A. Role prioritization of hydrogen production technologies for promoting hydrogen economy in the current state of China. Renew. Sust. Energ. Rev. 2015; 41: 1217-1229.

[3] Blyashko Ya I. Modern trends in the development of small hydro power around the world and in Russia. Thermal Engineering 2010; 57: 953-960.

[4] Shakya SR, Shrestha RM. Transport sector electrification in a hydropower resource rich developing country: energy security, environmental and climate change co-benefits. Energy Sustainable Dev. 2011; 15: 147-159.

[5] Stenzel P, Linssen J. Concept and potential of pumped hydro storage in federal waterways. Applied Energy 2016; 162: 486-493.

[6] Chang JS. Transients of hydraulic machine installations. 1st ed. BeiJing: Higher Education Press; 2005.

[7] Lund H. Renewable energy systems: the choice and modeling of $100 \%$ renewable solutions. 1st ed. NewYork: Academic Press; 2009.

[8] Zhang Q, Mclellan BC, Tezuka T, Ishihara KN. An integrated model for long-term power generation planning toward future smart electricity systems. Applied Energy 2013; 112: 1424-1437.

[9] Guo RP, Zhu XJ, Chen B, Yue YL. Ecological network analysis of the virtual water network within China's electric power system during 2007-2012. Applied Energy 2016; 168: 110-121. 
[10] Xu BB, Chen DY, Zhang H, Wang FF, Dynamic analysis and modelling of a novel fractional-order hydro-turbine-generator unit. Nonlinear Dynamics 2015; 81(3): 1263-1274.

[11] Zeng Y, Zhang LX, Guo YK, Qian J. Hamiltonian Stabilization Additional L-2 Adaptive Control and its Application to Hydro Turbine Generating Sets. International Journal of Control Automation and Systems 2015; 13: 867-876.

[12] Minakov AV, Platonov DV, Dekterev AA, Sentyabov AV, Zakharov AV. The numerical simulation of low frequency pressure pulsations in the high-head Francis turbine. Computers \& Fluids 2015; 111: 197-205.

[13] Beran V, Sedlacek M, Marsik F. A new bladeless hydraulic turbine. Applied Energy 2013; 104: 978-983.

[14] Zhang S, Andrews-Speed P, Perera P. The evolving policy regime for pumped storage hydroelectricity in China: A key support for low-carbon energy. Applied Energy 2015; 150: 15-24.

[15] Wei SP. Simulation of hydraulic turbine regulating system. 1st ed. Wuhan: Huazhong University of Science \& Technology Press; 2011. [in Chinese]

[16] Kichonge B, John GR, Mkilaha ISN. Modelling energy supply options for electricity generations in Tanzania. J. Energy South. Afr. 2015; 26: 41-57.

[17] Beevers D, Branchini L, Orlandini V, De Pascale A, Perez-Blanco H. Pumped hydro storage plants with improved operational flexibility using constant speed Francis runners. Applied Energy 2015; 137: 629-637. 
[18] Shen ZY. Hydraulic turbine regulation. 1st ed. Beijing: China Water \& Power Press; 1998.[in Chinese]

[19] Chen DY, Ding C, Ma XY, Yuan P, Ba DD. Nonlinear dynamical analysis of hydro-turbine governing system with a surge tank. Appl. Math. Model 2013; 37: 7611-7623.

[20] Gagliano, A, Tina GM, Nocera F, Patania F. Technical and Economic Perspective for Repowering of Micro Hydro Power Plants: a Case Study of an Early XX Century Power Plant. Energy Procedia 2014; 62: 512-521.

[21] Florides G, Kalogirou S. Ground heat exchangers - A review of systems, models and applications. Renw. Energ. 2007; 32: 2461-2478.

[22] Ardizzon G, Cavazzini G, Pavesi G. A new generation of small hydro and pumped-hydro power plants: Advances and future challenges. Renew. Sust. Energ. R. 2014; 31: 746-761.

[23] $\mathrm{Xu}$ BB, Wang FF, Chen DY, Zhang H. Hamiltonian modeling of multi-hydro-turbine governing systems with sharing common penstock and dynamic analyses under shock load. Energy Conv. Manag. 2016; 108: 478-487.

[24] Zeng Y, Zhang LX, Qian J, Guo YK. Control design method of Hamiltonian structure modified and its application. Electric Machines and Control 2014; 18. [In Chinese]

[25] Zhang H, Chen DY, Xu BB, Wang FF. Nonlinear modeling and dynamic analysis of hydro-turbine governing system in the process of load rejection transient. Energy Conv. Manag. 2015; 90: 128-137. 
[26] Chen DY, Ding C, Do YH, et al. Nonlinear dynamic analysis for a Francis hydro-turbine governing system and its control. Journal of the Franklin Institute: Engineering and Applied mathematics 2014; 351: 4596-4618.

[27] Gohir PP, Saini RP. Effect of temperature, suction head and flow velocity on cavitation in a Francis turbine of small hydro power plant. Energy 2015; 93: 613-624.

[28] Kundur P. Power system stability and control. 1st ed. New York: McGraw-Hill Professional; 1994.

[29] Ling DJ. Bifurcation and chaos of hydraulic turbine governor[D]. Nanjing: Hohai Universtiy; 2007. [In Chinese]

[30] Chilipi RR, Singh B, Murthy SS, Madishetti S, Bhuvaneswari G. Design and implementation of dynamic electronic load controller for three-phase self-excited induction generator in remote small-hydro power generation. IET Renew. Power. Generat. 2014; 8: 269-80.

[31] Huang SR, Chang PL, Hwang YW, Ma YH. Evaluating the productivity and financial feasibility of a vertical-axis micro-hydro energy generation project using operation simulations. Renw. Energ. 2014; 66: 241-250.

[32] Giosio DR, Henderson AD, Walker JM, Brandner PA, Sargison JE, Gautam P. Design and performance evaluation of a pump-as-turbine micro-hydro test facility with incorporated inlet flow control. Renw. Energ. 2015; 78: 1-6. 
[33] Carapellucci R, Giordano, Pierguidi F. Techno-economic evaluation of small-hydro power plants: Modelling and characterisation of the Abruzzo region in Italy. Renw. Energ. 2015; 75: 395-406.

[34] Hearn CS, Pratap SB, Chen DM, Longoria RM. Reduced-Order Dynamic Model of Permanent Magnet and HTSC Interaction in an Axisymmetric Frame. IEEE-ASME Trans. Mechatron. 2014; 19: 1226-1233.

[35] Pico HV, McCalley JD, Angel A, and et al. Analysis of very low frequency oscillations in hydro-dominant power systems using multi-unit modeling. IEEE T. Power Syst. 2012; 27: 1906-1915.

[36] Wang YZ, Cheng DZ, Li CW, Ge Y. Dissipative Hamiltonian realization and energy-based L(2)-disturbance attenuation control of multimachine power system. IEEE Trans. Autom. Control. 2003; 48: 1428-1433.

[37] Zhang QF, Karney B, Suo LS, Colombo AF. Stochastic Analysis of Water Hammer and Applications in Reliability-Based Structural Design for Hydro Turbine Penstocks. J. Hydraul. Eng. -ASCE. 2011; 137: 1509-1521.

[38] Van Casteren JFL, Bollen MHJ, Schmieg ME. Reliability assessment in electrical power systems: The Weibull-Markov stochastic model. IEEE Trans. Ind. Appl. 2000; 36: 911-915.

[39] Erokhin V, Berzina T, Gorshkov K, and et al. Stochastic hybrid 3D matrix: learning and adaptation of electrical properties. J. Mater. Chem. 2012; 22: 22881-22887. 
[40] Rahman MM, Khan MMUH, Ullah MA, Zhang XL, Kumar A. A hybrid renewable energy system for a North American off-grid community. Energy 2016; 97: 151-160.

[41] Huang YF, Liu GN, Fan SY. Research on prototype hydro-turbine operation. 1st ed. Beijing: China Electric Power Press; 2010.[in Chinese] 